\title{
Molecular Characterization of Trichoderma Mutants with RAPD and ISSR Marker
}

\author{
Radhika Deshmukh*, S.T. Ingle, S.S. Mane and P.N. Davhale \\ Department of Plant Pathology, Post Graduate Institute, Dr. PDKV Akola (MS) 444104, India \\ *Corresponding author
}

\begin{tabular}{|l|}
\hline Ke y w o r d s \\
$\begin{array}{l}\text { Trichoderma mutants, } \\
\text { DNA extraction, RAPD } \\
\text { marker, ISSR marker } \\
\text { Scorable bands }\end{array}$ \\
\hline Article Info \\
\hline $\begin{array}{l}\text { Accepted: } \\
\text { 20 September } 2018 \\
\text { Available Online: } \\
\text { 10 October } 2018\end{array}$ \\
\hline
\end{tabular}

A B S T R A C T

Trichoderma is an important biocontrol agent of several soil borne plant pathogens. Genetic modification using mutagenesis offers the potential for producing improved bio protection is likely to enhance their biocontrol capabilities against soil borne pathogen. Molecular techniques are important analytical tool to characterized genetic variability and diagnosis of microbial population. Molecular variability of Trichoderma mother culture and its mutants was studied by using Random Amplified Polymorphic DNA (RAPD). 20 RAPD primer of OPA series were tested, of which 14 primers produced 72 scorable bands among them 52 bands were polymorphic and level of polymorphism was upto $72 \%$. On the basis of dendrogram, the tested cultures were clearly divided into 2 groups. First group i.e. cluster A included 4 mutants TvM-5, TvM-3, TvM-1 TvM-2 and mother culture TvMC. Second group i.e. cluster B included only one mutant i.e. TvPM-4. In ISSR 6 primers were tested, of which, 6 primer produced 32 scorable bands among which 27 bands were polymorphic and level of polymorphism was upto $84 \%$. Two clusters were observed in Dendrogram i.e. Cluster A includes four mutants TvM-5, TvM-3, TvM-1, TvM-2 and mother culture TvMC and cluster B contained only one mutant i.e. TvPM-4.

\section{Introduction}

Trichoderma is used in different crop like rice, wheat, pulses (black gram, cowpea, and chickpea) vegetable (tomato, brinjal, and chili) against a wide range of plant pathogen. One of the popular species, Trichoderma viride is effective against all soil borne fungal pathogen like Phytophthora, Fusarium, Pythium, Rhizoctonia, Sclerotium. Trichoderma, reduce growth, survival or infection caused by pathogen by different mechanism. In addition, some species of the genus are economically important producers of industrial enzymes
(Trichoderma reesei, Hypocreajecorina; and antibiotics (Sivasithamparam and Ghisalberti, 1998). Trichoderma is easily identified in culture media, which produces large number of characteristics small, green or white conidia, from phialides present on the profusely or meagrely branched conidiophores. However, the identification of isolates to species level is difficult and confusing due to the complexity and closely related characters of the species. Trichoderma isolates were differentiated by mycelial growth rate and colony appearance, as well as microscopic morphological features, including 
phialides and spores. These can also be distinguished by molecular techniques like DNA sequencing, Random Amplification of Polymorphic DNA (RAPD) analysis, Restriction Fragment Length Polymorphism (RFLP) analysis, internal transcribed sequences (ITS) of the ribosomal DNA (rDNA) analysis (rDNA-ITS1) and universally primed polymerase chain reaction (UP-PCR) have been used to characterize isolates of Trichoderma (Cumagun et al., 1999).

Inter simple sequence repeats (ISSR) have been used as another effective method to characterize genetic variability. Since the evolutionary rate within ISSR is considerably higher than other types of DNA, the likelihood of finding polymorphism is greater compared to RAPD. Since the first reports of RAPD markers by (Williams et al., 1990). This method has been widely used for identification of species. This technique has been used in some cases for species identification.

\section{Materials and Methods}

Trichoderma viride mother culture and four mutants i.e. ( $6^{\text {th }}$ generation) irradiated with gamma rays (Cobalt 60) @ 41.6 gray/minute at BARC, Trombay, Mumbai were collected from Department of Plant Pathology Dr. Panjabrao Deshmukh Krishi Vidyapeeth, Akola. The applied doses level of gamma rays was $75 \mathrm{k}$-rad with time interval of $15,30,45$ and 60 minutes. One T.viride mutant was collected from G.B. Pant University of Agriculture and Technology, Pantnagar. This mutants can be coded as Trichoderma viride mother culture (TvMC), Trichoderma viride mutant (T.Viride@ 75 k-rad 15 min.TvM-1), Trichoderma viride mutant (T.Viride@ 75 krad 30 min.TvM-2) Trichoderma viride mutant (T.Viride@ 75 k-rad 45 min. TvM-3) Trichoderma viride mutant (Pantnagar TvPM4), Trichoderma viride mutant (T.Viride@ 75 k-rad 60 min. TvM-5).

\section{Extraction of DNA}

Genomic DNA was isolated from the twenty four selected isolates by the cetyl dimethyl ethyl ammonium bromide (CTAB) method (Murray and Thompson, 1980) with some modifications. For extraction of DNA seven days old mycelial mat was transferred on sterilized blotter paper, air dried to remove moisture. Dried mycelium mat was used for DNA isolation. Approximately, one gram of air dried fungal mat was quickly frozen in liquid nitrogen $\left(-196^{\circ} \mathrm{C}\right)$ and crushed into powder form with the help of sterilized mortar and pestle. The powder was immediately homogenized by adding pre-warmed $\left(65^{\circ} \mathrm{C}\right)$ extraction buffer and transferred to two $\mathrm{ml}$ Eppendorf tubes. These tubes were incubated in a water bath at $65^{\circ} \mathrm{C}$ for one hour with gentle shaking at every 15 minutes then add an equal volume of chloroform : isoamyl alcohol (24:1) and centrifuged at $12000 \mathrm{rpm}$ at room temperature for 20 minutes. Then aqueous phase transferred to another tube and equal volume of ice chilled Isopropanol was added. Centrifuged for 10 minutes at $12000 \mathrm{rpm}$ and decanted the supernatant. The pellet was washed with 70 per cent ethanol twice and suspended in $\mathrm{T}_{50} \mathrm{E}_{10}$ buffer (50 mMTris- $\mathrm{HCl}$, $\mathrm{pH}$ 8.0, $10 \mathrm{mM}$ EDTA). The DNA solution was treated with RNase at $37^{\circ} \mathrm{C}$ for $1 \mathrm{hr}$ and stored at $-20^{\circ} \mathrm{C}$ until needed.

\section{PCR Reaction for RAPD and ISSR marker}

The PCR cycle was carried out in small reaction tubes, containing a reaction volume typically of $12.5 \mu \mathrm{l}$ in which10x Taq buffer $1.25 \mu \mathrm{l}, \mathrm{MgCl}_{2}(25 \mathrm{mM} 1.25 \mu \mathrm{l})$, dNTPs $(10$ $\mathrm{mM} 0.3 \mu \mathrm{l}), \mathrm{Taq}$ polymerase $(5 \mathrm{U} / \mu 10.3 \mu \mathrm{l})$, Sterile distilled water $(5.4 \mu \mathrm{l})$, Primer $(1.0 \mu \mathrm{l})$, Template DNA $(37.5 \mathrm{ng} 2.0 \mu \mathrm{l})$ that was inserted into a thermal cycler (Eppendorf) that heated and cooled the reaction tubes within it to the precise temperature required for each step of the reaction. The PCR cycle was as 
follows initial denaturation at $94^{\circ} \mathrm{C}$ for $5 \mathrm{~min}$, Denaturation at $94^{\circ} \mathrm{C}$ for $1 \mathrm{~min}$, Annealing $35^{\circ} \mathrm{C}$ for $1 \mathrm{~min}$ (for RAPD and its specific to each primer for ISSR) Extension $72^{\circ} \mathrm{C}$ for $3 \mathrm{~min}$ and Final Extension $72^{\circ} \mathrm{C}$ for $10 \mathrm{~min}$. With 35 cycles. 20 primers were screened, consisting of RAPD primer of OPA series 1to 20 from Genaxy Scientific Pvt. Ltd. to evaluate the variability among Trichoderma viride mother culture and mutants. The PCR amplified product of each primer was resolved on $1.2 \%$ agarose gel electrophoresis and the amplified product was compared with $1 \mathrm{~kb}$ DNA ladder for RAPD and 100bp for ISSR.

\section{Results and Discussion}

\section{Internal Transcript Spacer (ITS) analysis}

For the confirmation of Trichoderma viride mother culture and mutants ITS marker was done with using ITS-1 and ITS-4 primer which gives band size in the range of 500bp to $600 \mathrm{bp}$. the result are in accordance with Chakraborty (2010) who studied the identification and genetic variability of
Trichoderma isolates which observed amplified DNA fragment approximately 600bp.

\section{RAPD analysis}

The genomic DNA of five Trichoderma mutants and one mother culture of Trichoderma viride was amplified. Molecular variability of Trichoderma viride mother culture and mutants was studied by using 14 RAPD primers of OPA series of which 14 primers produced 72 scorable bands. Among the 72 scorable bands the 52 bands were polymorphic and level of polymorphism was $72 \%$ (Table 1).

\section{ISSR analysis}

The genomic DNA of five Trichoderma mutants and one mother culture of Trichoderma viride was amplified. Six ISSR primers screened for Trichoderma viride mother culture and mutants produced reproducible and scorable bands with high degree of polymorphism (Table 2).

Table.1 Per cent polymorphism observed in RAPD primer

\begin{tabular}{|c|c|c|c|c|}
\hline Sr. & Primer & Total bands & Polymorphic bands & $\%$ polymorphism \\
\hline 1 & OPA-1 & 6 & 4 & $66.66 \%$ \\
\hline 2 & OPA-4 & 7 & 5 & $71.42 \%$ \\
\hline 3 & OPA-5 & 3 & 2 & $66.6 \%$ \\
\hline 4 & OPA-9 & 6 & 5 & $83.33 \%$ \\
\hline 5 & OPA-10 & 7 & 6 & $85.7 \%$ \\
\hline 6 & OPA-11 & 5 & 4 & $80 \%$ \\
\hline 7 & OPA-12 & 6 & 3 & $50 \%$ \\
\hline 8 & OPA-13 & 5 & 3 & $60 \%$ \\
\hline 9 & OPA-14 & 2 & 2 & $100 \%$ \\
\hline 10 & OPA-15 & 4 & 3 & $75 \%$ \\
\hline 11 & OPA-16 & 9 & 6 & $66.6 \%$ \\
\hline 12 & OPA-17 & 5 & 4 & $80 \%$ \\
\hline 13 & OPA-18 & 4 & 3 & $75 \%$ \\
\hline 14 & OPA-19 & 3 & 2 & $66 \%$ \\
\hline & TOTAL & 72 & 52 & $72 \%$ \\
\hline
\end{tabular}


Table.2 Percent polymorphism observed in ISSR primer

\begin{tabular}{|l|l|c|c|c|}
\hline \multicolumn{1}{|c|}{ Sr. No. } & Primer & Total bands & Polymorphic band & \% polymorphism \\
\hline $\mathbf{1}$ & AC8YT & 5 & 4 & $80 \%$ \\
\hline $\mathbf{2}$ & GA8C & 5 & 5 & $100 \%$ \\
\hline $\mathbf{3}$ & CT8RG & 6 & 4 & $66.66 \%$ \\
\hline $\mathbf{4}$ & GA8YT & 5 & 4 & $80 \%$ \\
\hline $\mathbf{5}$ & AG8T & 4 & 4 & $100 \%$ \\
\hline $\mathbf{6}$ & GA9RY & 7 & 5 & $71 \%$ \\
\hline & TOTAL & 32 & 27 & $84 \%$ \\
\hline
\end{tabular}

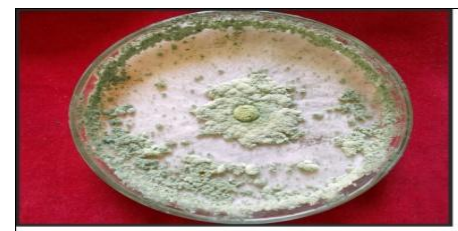

TrMC

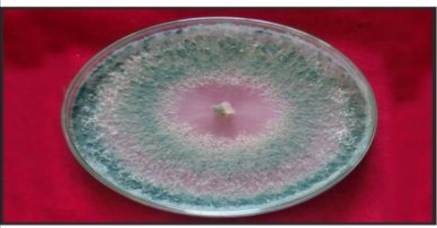

TVM-2

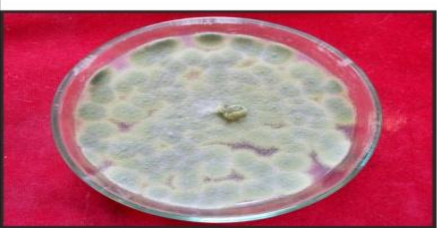

TVPM-4

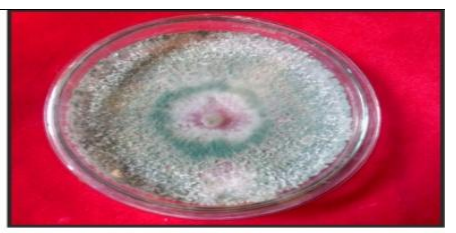

TvM-1

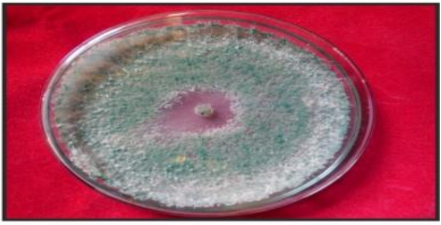

TvM-3

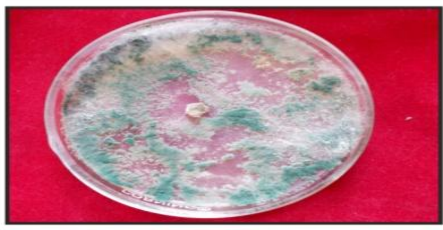

TVM-5

Plate 1. Trichoderma viride mother culture and mutants $\left(6^{\text {th }}\right.$ generation) used for morphological and molecular study

Plate.2 Conformation and identification of Trichoderma mutants by using ITS primer

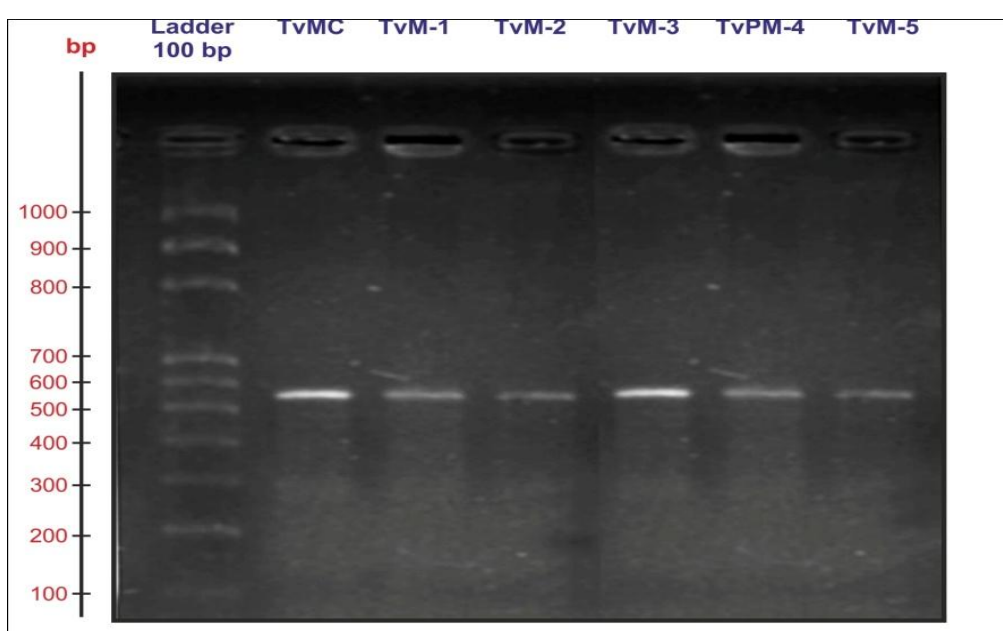


Plate.3 RAPD analysis of Trichoderma mutants using OPA-12 and OPA-4 primers
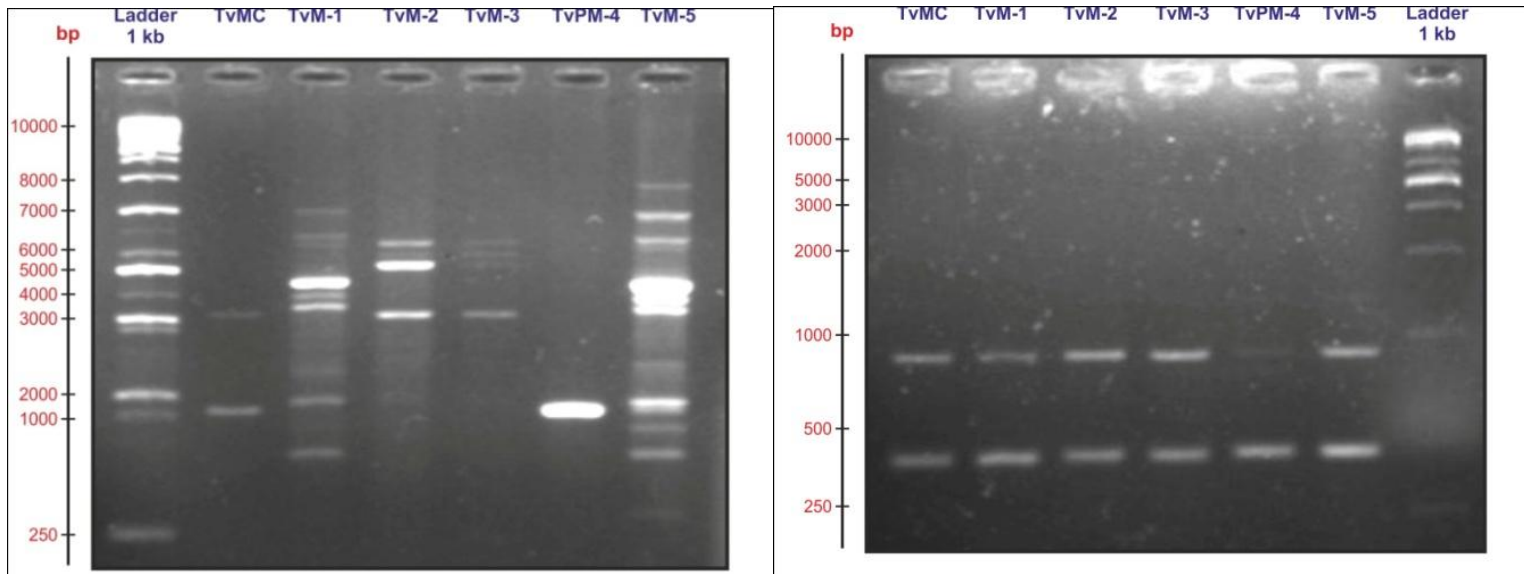

Plate.4 RAPD analysis of Trichoderma mutants using OPA-12 and OPA-13 primers
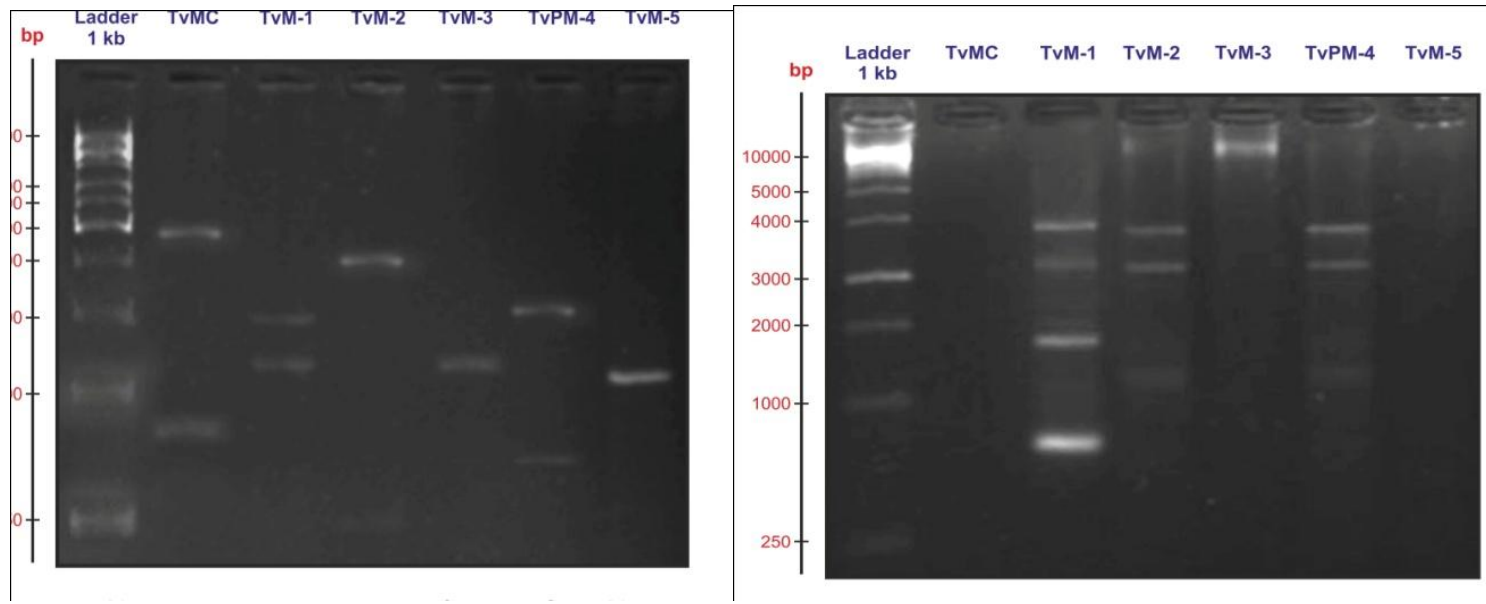

Plate.5 RAPD analysis of Trichoderma mutants using OPA-10 and OPA-11 primers

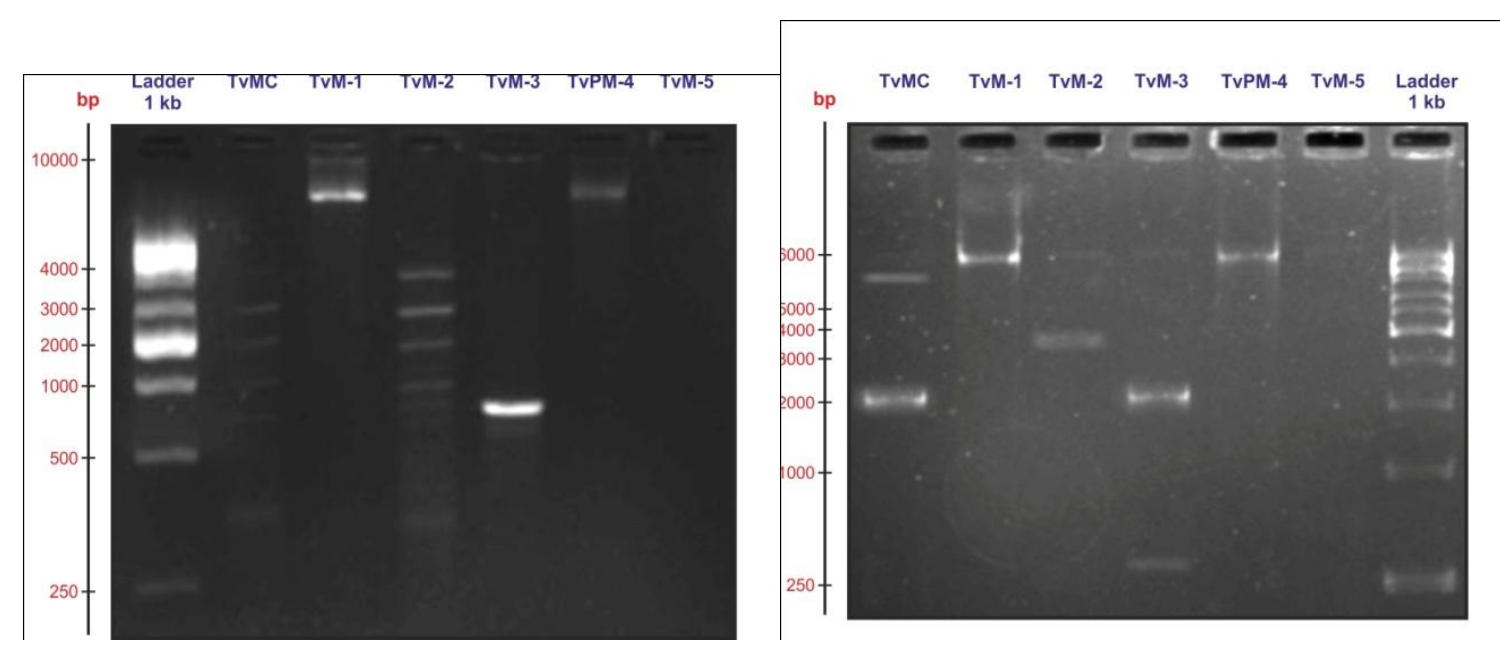


Plate.6 ISSR analysis of Trichoderma mutants using AC8YT and GA8C primers.

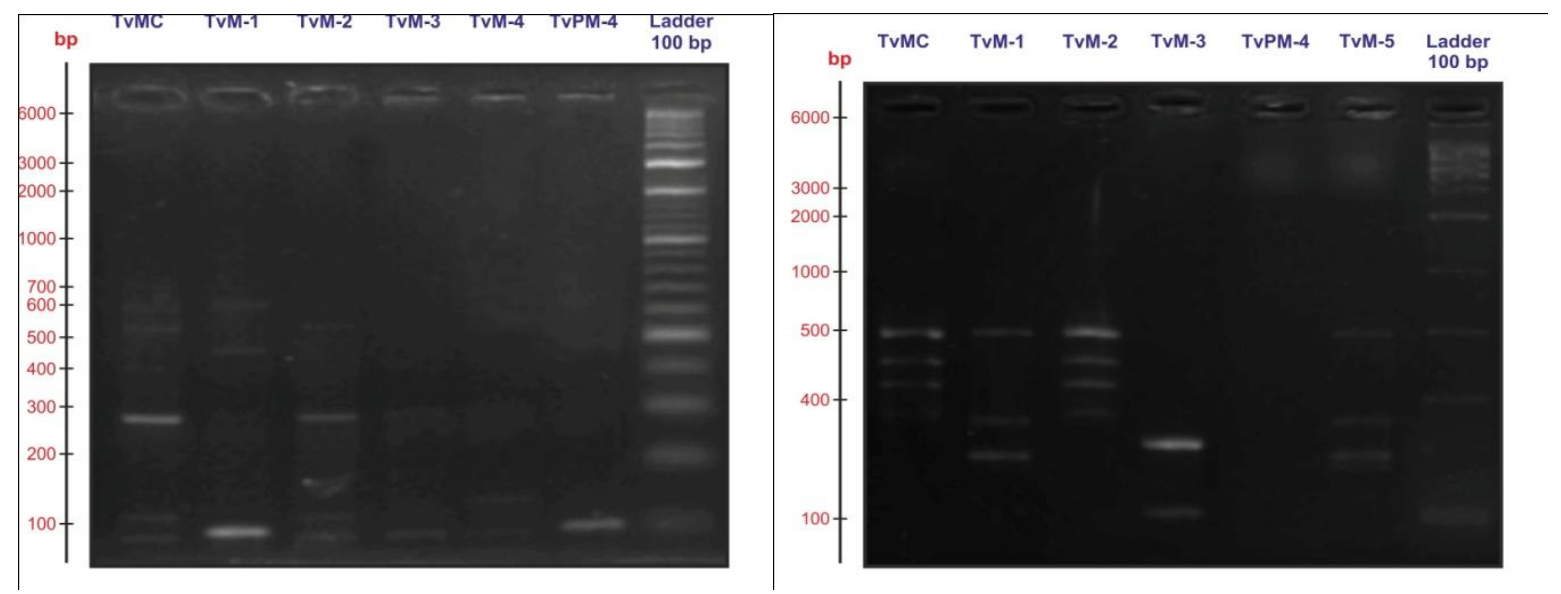

Plate.7 ISSR analysis of Trichoderma mutants using AG8T and GA9RY
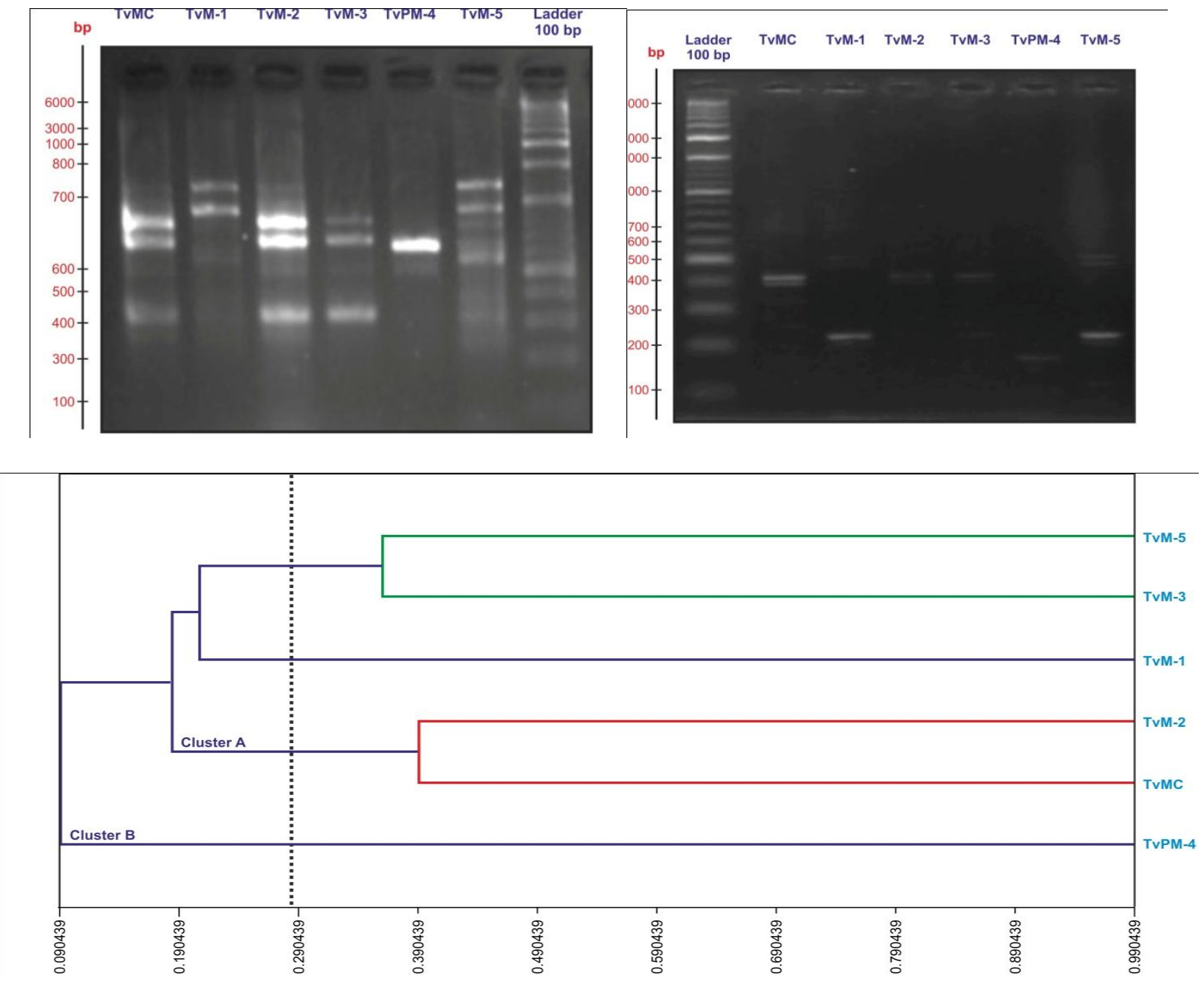

Fig. 1. RAPD UPGMA dendrogram of RAPD analysis of Trichoderma viride mother culture and mutants based on Jaccard's similarity coefficient 
Fig.2 ISSR UPGMA Dendrogram of ISSR analysis of Trichoderma mother culture and mutants

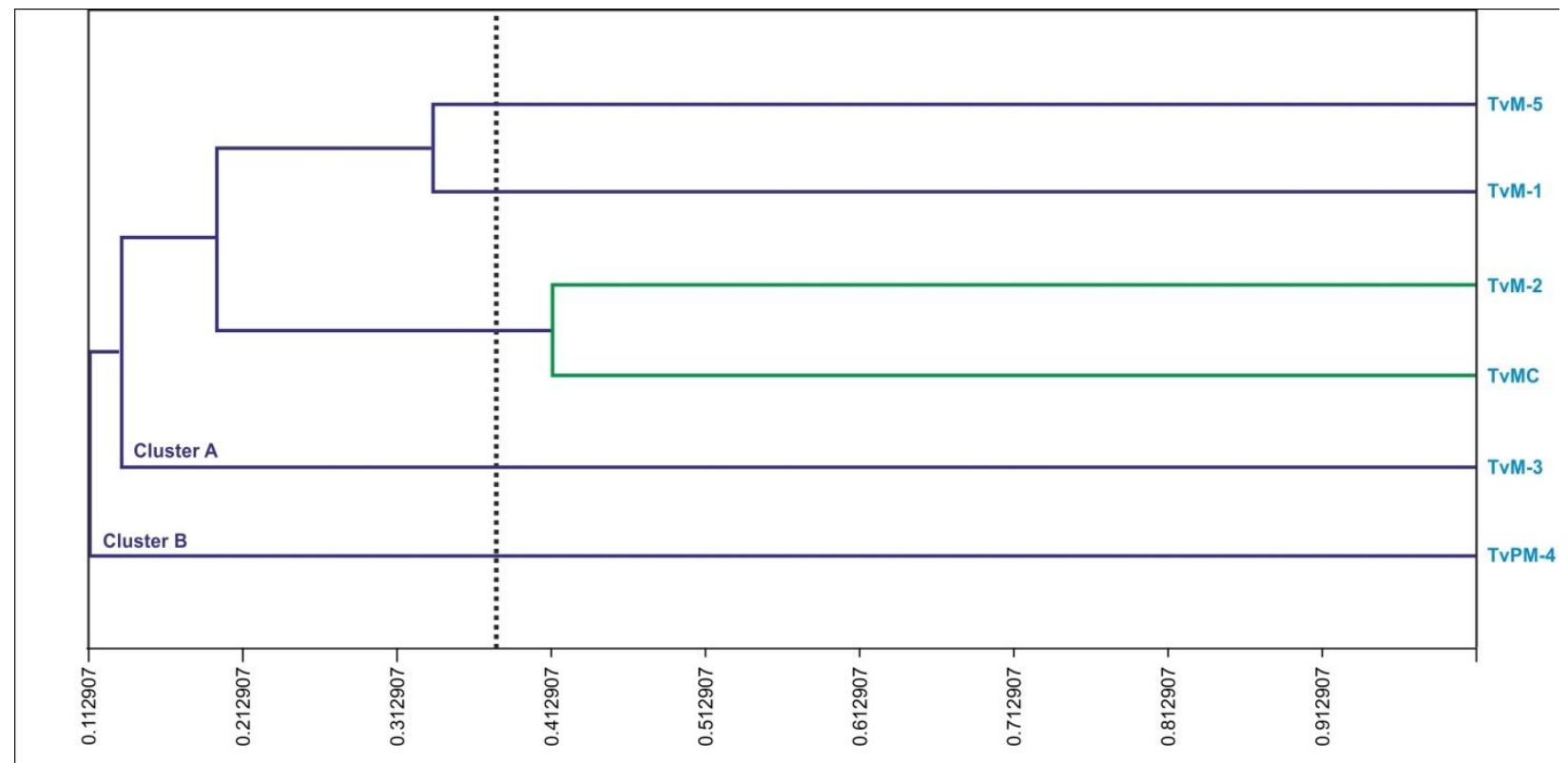

Molecular variability of Trichoderma viride mother culture and mutants was studied by using 6 primers of which 6 primers produced 32 scorable bands. Among the 32 scorable bands the 27 bands were polymorphic and level of polymorphism was $84 \%$.

A binary similarity matrix of combined data from 14 RAPD primers and 6 ISSR primers of Trichoderma viride mother culture and mutants were prepared by scoring presence or absence of band (Fig. 1 and 2).

The same molecular weight was assumed to be identical. On the basis of calculated similarity matrix the similarity between genotypes can be predicted. The genotypes showing similarity index " 1 " are presumed to be $100 \%$ similar while that of " 0 " are $100 \%$ genetically dissimilar.

In present study of RAPD Primer the similarity coefficient value ranged from 0.370 to 0.000 across Trichoderma viride mother culture and mutants while it in ISSR is ranged from 0.409 to 0.050 indicating high degree of polymorphism in respect to genetic similarity. Genetic similarity estimate (Jaccard's coefficient) based on RAPD and ISSR banding pattern was used for cluster analysis to present genetic relationship in the form of dendrogram.

Two major clusters were obtained on the basis of analysis in both RAPD and ISSR marke, First group is named as cluster $-\mathrm{A}$, includes TvM-5,TvM-3,TvM-1,TvM-2,TvMC.Second group is named as cluster $-\mathrm{B}$ which includeTvPM-4.

In RAPD the TvMC was found to have a higher similarity index with TvM-2. The TvPM-4 with TvM-3 and TvPM-4 with TvMC was found to have a lower similarity index and in ISSR the TvM-2 was found to have a higher similarity index with TvMC. The TvM-5 with TvPM-4 was found to have a lower similarity index.

\section{References}

Agrawal, T. and A.S. Kotasthane. 2009: Assessment of diversity in isolates of Trichoderma species from soils of Chhattisgarh region in Central India using RAPD markers. J. Mycol. Plant Pathology. 139(3): 484-489. 
Chakraborty, B.N., U. Chakraborty, A. Saha., P.L. Dey and K. Surnar. 2010: Molecular Characterization of Trichoderma viride and Trichoderma hazarium Isolated from soil from north Bengal based on rDNA marker and analysis of their PCR-RAPD profiles. Global J. Biotech. and Biochem. 5(1): 55-61.

Cumagun, C.J., J. Hockenhull and M. Lubeck. 1999. Identification characterization of Trichoderma isolates from Phillipine rice yields by UP-PCR and rDNA ITSI analysis. Res. Program. Plant Protect. Plant Nutrition. pp 37-47.

Hermosa, M.R., I. Grondona, E.A. Iturriaga., J.M. Diaz-Minguez., C. Castro and E. Monte. 2001: Molecular characterization and identification of biocontrol isolates of Trichoderma species. Appl. Environ. Microbiol. 66: 1890-1898

Murray, M.G. and W.F. Thompson. 1980. Rapid isolation of high molecular weight plant DNA Cambridge Institution of Washington, Department of Plant Biology, Stanford, CA 94305, USA, Volume 8.

Muthumeenaksh, S., A.E. Brown and P.R. Mills. 1998: Genetic comparison of the aggressive weed mould strains of Trichoderma harzianum from mushroom compost in North America and the British Isles. Mycol. Res. 102: 385-390.

Naher, L., U. Yusuf, A. Ismail and K. Hossain, 2014: Trichoderma Spp.: A Biocontrol Agent for Sustainable Management of Plant Diseases. Pak. J. Bot. 46(4): 14891493.

Persoon, C.H. 1794: Disposition methodsicafungorum, Romersneues Mag. Bot. 1: 8-128.
Qian, Y.E., Y.X. Qiu., J.X. Yan-qi., S. Zhao and F. Cheng-xin. 2006: J. Zhejiang Univ. Sci., 7(11): 868-872.

Rifai, M.A., 1969. A revision of the genus Trichoderma. Mycological Papers. 116:156.

Shafique, S. and R. Bajwa. 2011: Strain improvement in Trichoderma viride through mutation for over expression of cellulase and characterization of mutants using random amplified polymorphic DNA (RAPD) African Journal of Biotechnology, 10(84) : 19590-19597.

Shahbazi, S., H.A. Fallah., H. Askari and M.A. Ebrahimi. 2017: Molecular marker based diagnosis of genetic diversity in gamma mutated Trichoderma spices. International Journal of Agricultural and Environmental Research. 3(1): 56-71.

Siameto, E.N., S. Okoth., N.O. Amugune and N. Chege. 2011: Molecular characterization and identification of biocontrol isolates of Trichoderma harzianum from Embu district, Kenya. Trop. Subtrop. Agroecosys. 13:81-90.

Sivasithamparam, K. and F.L. Ghisalberti. 1998: Secondary metabolism Trichoderma and Gliocladium. Volume I. Taylor and Francis Ltd. London. pp 139191.

Williams, J.G.K., A.R. Kubelik., K.L. Livak., J.A. Rafalski and S.V. Tingey. 1990: DNA polymorphisms amplified by arbitrary primers are used as genetic marker, Nucleic Acids Res., 18:65316535.

Zimand, G., L. Valinsky., Y. Elad., I. Chet and S. Manulis. 1994: Use of RAPD procedure for the identification of Trichoderma strains, Mycol. Res. 98: 531-534.

\section{How to cite this article:}

Radhika Deshmukh, S.T. Ingle, S.S. Mane and Davhale, P.N. 2018. Molecular Characterization of Trichoderma Mutants with RAPD and ISSR Marker. Int.J.Curr.Microbiol.App.Sci. 7(10): 27912798. doi: https://doi.org/10.20546/ijcmas.2018.710.324 